\title{
Interactive methods of teaching mathematics, contributing to the formation of competencies in students of the field of training Agronomy format
}

\author{
Pavel Kiyko, ${ }^{1, *}$, and Natalia Shchukina ${ }^{1}$ \\ Omsk SAU, 1 Institutskaya Square, 1, 644008 Omsk, Russia
}

\begin{abstract}
The article outlines aspects of the formation of general professional competencies (GPC-1) through the study of mathematical disciplines; reveals the features of the methodology for the application of tasks (tasks of profile content, task case, task-situation), which are the main means of assessing the formation of the corresponding indicators of achievement of competence: ID-1, ID-2, ID-3, etc. The work analyzed educational publications in mathematical disciplines for the presence of tasks for an objective assessment of the level of formation of general professional competence (GPC-1), the problem of developing the content of criteria and assessment tools for formation of general professional competencies. The authors provide examples of tasks in the disciplines of Higher Mathematics and Mathematics and Mathematical Statistics, designed to form skills in identifying and defining a problem, choosing research methods, analyzing, interpreting the result and transferring fundamental knowledge into the language of professional activity.
\end{abstract}

\section{Introduction}

In the existing FSES HE the mandatory requirements to results of development of sample principal educational program (SPEP) of a bachelor degree are declared, which is a combination of universal cultural and professional competences, which in turn should ensure the professional competence of the graduate, including future AIC expert.

\subsection{Problem Statement}

It is obvious that competencies are not formed by a single discipline or course, they are gradually formed and improved from discipline to discipline, from course to course. This statement applies to all competencies, including general professional ones, which are formed throughout education and further improved during professional activity. In that way considered under this article, GPC-1 (Capable of solving typical problems of professional activities on the basis of knowledge of the fundamental laws of mathematical, natural

\footnotetext{
* Corresponding author: pv.kiyko@omgau.org
} 
scientific and general professional disciplines with the use of information and communication technologies) for major 35.03.04 Agronomy, according to the working curriculum for the bachelor begins its formation in the process of disciplines development unit 1, taught by general education departments (of Mathematical Sciences), continues to evolve and develop with the help of disciplines taught by graduate departments, (in the cycle of general and professional disciplines), then in the process of educational practice unit 2, monitoring and analysis of formation which is carried out in preparation for pass and the pass of state examination - unit 3.

Indicators of competence achievement of GPC-1, which are formed during the development of mathematical disciplines, are set in the SPEP:

AI-1 demonstrates knowledge of the basic laws of mathematical disciplines necessary for solving typical problems in the field of agronomy;

AI-2 uses knowledge of the basic laws of mathematical sciences to solve standard problems in agronomy;

AI-3 uses information and communication technologies to solve typical problems in the field of agronomy.

\section{Research issues}

\subsection{Purpose of research}

The purpose of this study is to develop the content of criteria and assessment tools for an objective assessment of the level of general professional competence formation in a student based on the diagnosis of relevant indicators at different stages of mathematical disciplines mastering on the example of the discipline "B1.0.09 Mathematics and Mathematical Statistics".

The main means of assessing the formation of the relevant indicators of GPC-1 are problems. It is important to note that students should be offered a set of problems in which the mental activity of students increases, and it increases when the thought comes across something new, for example, a problem condition with a profile context, an unusually formulated problem requirement, a non-standard representation of mathematical data, etc. Such conditions are met by profile content problems, case tasks, for which there is no ready-made template, considered in textbooks or in the classroom. The importance of problems in the practice of teaching with mathematical disciplines is quite difficult to overestimate. It is important for the student to understand not just how to solve certain mathematical problems, but also to master such techniques that will develop thinking and help to carry out the transfer of mathematical educational results for solving problems in professional activities. The result of the development of cognitive, mental activity is the mental independence of the individual, which is manifested in solving various kinds of problems and tasks.

\section{Research methods}

Consider the content of the discipline B1.O.09 Mathematics and Mathematical Statistics module "Statistical estimates of distribution parameters". The set of tasks for assessing the formedness of GPC is represented by the following types:

- problem with mathematical content.

Before analyzing and solving problems of profile content and case tasks, it is important to work out the student digestion of basic concepts and formulas, such as: variational series, numerical characteristics, etc., which are the foundation for mastering this topic. The 
content of such problems is formulated exclusively in mathematical language. It has one correct solution.

- problem with profile content.

This type of problems is aimed at the formation of techniques aimed at transferring mathematical knowledge and skills to the language of professional activity. The content of such problems is formulated exclusively in the language of future professional activity. It has at least one correct solution.

- case-task (problem-situation).

This type of problems is aimed not only at the formation of techniques aimed at transferring mathematical knowledge and skills to the language of professional activity, but also at assessing the formation of GPC. The content and requirements of such problems is formulated exclusively in the language of future professional activity. It has at least one correct solution, but only one of them is optimal.

Considering indicators of achievement of the competence of GPC-1, we present examples of these problem types on the above integrated unit and present levels of GPC development in accordance with the indicators.

It is obvious that the GPC formation is a level one. Problems with mathematical content are aimed at GPC forming at a critical and/or acceptable level. Problems with profile content are associated with the GPC formation at an acceptable and/or optimal level. Case tasks assume the GPC development at an optimal and/or high level.

Problem with mathematical content.

Problem 1.1. As a result of the tests, the value of $\mathrm{X}$ took several values:

$8, \quad 8, \quad 7,9, \quad 9, \quad 9, \quad 10,10,10, \quad 8,9, \quad 10,12 \quad 12,12,10,14$, $9, \quad 7, \quad 7, \quad 12,14,12,12,10$.

The following is required:

1) to create a discrete variation series with the corresponding frequencies and relative frequencies. To build a relative frequencies polygon (AI-1);

2) write down the formulas for calculating the average variance, and mean square deviation of the sample population (AI-1);

3) to calculate the average variance, and mean square deviation of the sample population (AI-2);

4) to calculate the mode, median, coefficient of variation, evaluations of mathematical expectation, variance, and mean square deviation (AI-2);

5) to determine the confidence interval in which the mathematical expectation and the mean square deviation (AI-2) are located with a reliability of 0.99 ;

6) perform a verification of the implementation of cl. 2 and cl. 3. using ICT (AI-3).

Problem 1.2. As a result of the test, the random variable $\mathrm{X}$ took a number of values:

$\begin{array}{ccccccccccccccccc}4.6 & 5.0 & 4.5 & 4.7 & 4.6 & 5.0 & 6.0 & 6.2 & 6.4 & 4.8 & 4.9 & 4.7 & 4.5 & 4.9 \\ 5.1 & 6.4 & 5.9 & 5.8 & 5.0 & 6.4 & 4.8 & 4.4 & 5.6 & 5.5 & 4.7 & 4.8 & 5.0 & 6.2 & 6.1 \\ 6.3 & 4.5 & 6.2 & 6.0 & 4.8 & 4.9 & 6.0 & 6.4 & 6.2 & 5.8 & 5.9 & 4.9 & 5.2 & 5.1 & 4.5 \\ 5.1 & 5.0 & 5.5 & 5.6 & 6.0 & 6.4 & & & & & & & & & \end{array}$

The following is required:

1) to create interval series, build a histogram of relative frequency density and empirical density curve (AI 1);

2) to calculate the average variance, and mean square deviation of the sample population (AI-1,2);

3) to calculate the mode, median, coefficient of variation, evaluations of mathematical expectation, variance, and mean square deviation (AI 1,2);

4) to calculate the average error of the sample average and the boundaries in which the average of the general population is located with a probability of 0.95 (AI 1,2).

5) perform a verification of the implementation of cl. 2 and cl. 3. using ICT (AI-3). 
Profile content problem.

The influence of sowing methods on the development and productivity of carrots of the

$\mathrm{K}$ variety is studied. Carrots were sown in two ways:

Method 1 (20 plots) This is the average weight of one carrot:

$120,135,188,176,176,135,188,188,191,190,189,189,176,176,135,184,184$, $188,190,190$

Method 2 (20 plots) This is the average weight of one carrot:

$171,176,189,178,178,183,125,189,190,176,190,189,176,178,176,183,183$, $188,190,125$

Problem 2.1.

1. Form the purposes and objectives of the study (AI-2),

2. Select the mathematical objects that correspond to the purpose of the study (AI 1),

3. Write down the mathematical formulas and laws necessary for the solution (AI 1)

4. Form a professional problem in mathematical language (AI 2).

Problem 2.2.

1. Build discrete distributions for each method of root crops planting (AI 1).

2. Calculate the sample characteristics for each distribution (AI 1,2),

3. Calculate the indicators that characterize the variability of the studied trait (AI $1,2)$.

Problem 2.3.

1. Build interval distributions for each method of root crops planting (AI 1).

2. Calculate the sample characteristics for each distribution (AI 1,2),

3. Calculate the indicators that characterize the variability of the studied trait (AI $1,2)$

4. Perform a comparative analysis of the found indicators (AI 2) and perform a performance check using ICT (AI-3).

5. Reveal the influence of sowing methods on the development and productivity of carrots of the $\mathrm{K}$ variety and draw conclusions, give recommendations for sowing this variety of carrots (AI 2)

Case task. (AI 1) (AI 2) (AI 3)

The agronomist of the farm solves the problem of increasing the yield of carrots of the $\mathrm{K}$ variety. It is known that sowing carrots can be carried out in two ways: method 1 (widerow single-line method), method 2 (four-line tape method). This farm could use any method of sowing carrots of this variety (financial costs are the same). The agronomist studies statistical data that characterize the influence of sowing methods on the productivity of carrots of the $\mathrm{K}$ variety on land plots that are similar in basic characteristics to the land fund of this farm. The statistical data of the methods are given above.

Analyze the situation. Come up with a technological solution that would increase the yield of carrots. Solution development should be based on knowledge of sample characteristics and statistical estimates of distribution parameters.

The correspondence of the levels of formedness of GPC-1 and indicators of competence achievement are presented in Table 1. 
Table 1. The correspondence of the levels of formedness and indicators of achievement.

\begin{tabular}{|c|c|c|}
\hline $\begin{array}{l}\text { GPC-1 } \\
\text { levels }\end{array}$ & Indicators of competence achievement & $\begin{array}{l}\text { Number of points } \\
\text { scored out of a } \\
\text { maximum of } 10\end{array}$ \\
\hline critical & $\begin{array}{l}\text { AI-1 demonstrates knowledge of some sample characteristics } \\
\text { necessary for solving typical problems in the field of agronomy, } \\
\text { there is no independence } \\
\text { AI-2 calculates some sample characteristics necessary for } \\
\text { solving standard problems in agronomy, there is no } \\
\text { independence } \\
\text { AI-3 does not use information and communication technologies } \\
\text { when searching for missing information and calculating some } \\
\text { sample characteristics, there is no independence }\end{array}$ & $0-4$ (less than $50 \%)$ \\
\hline acceptable & $\begin{array}{l}\text { AI-1 demonstrates knowledge of the sample characteristics } \\
\text { necessary to solve typical problems in the field of agronomy, } \\
\text { but only based on recommendations } \\
\text { AI-2 calculates sample characteristics for solving standard } \\
\text { problems in agronomy, but only based on recommendations } \\
\text { AI-3 uses information and communication technologies to } \\
\text { search for missing information, based on recommendations }\end{array}$ & $\begin{array}{l}5-6 \text { (more than } 50 \\
\text { and less than } 70 \% \text { ) }\end{array}$ \\
\hline optimal & $\begin{array}{l}\text { AI-1 demonstrates knowledge of sample characteristics and } \\
\text { statistical estimates necessary for solving typical problems in } \\
\text { the field of agronomy (pedagogical support of the teacher is } \\
\text { possible) } \\
\text { AI-2 calculates sample characteristics and statistical estimates } \\
\text { for solving standard problems in agronomy (teacher support is } \\
\text { possible) } \\
\text { AI-3 uses information and communication technologies when } \\
\text { searching for missing information (pedagogical support of the } \\
\text { teacher is possible) }\end{array}$ & $\begin{array}{c}7-8 \text { (more than } 70 \\
\text { and less than } 90 \% \text { ) }\end{array}$ \\
\hline high & $\begin{array}{l}\text { AI-1 demonstrates knowledge of sample characteristics and } \\
\text { statistical estimates necessary for solving typical problems in } \\
\text { the field of agronomy } \\
\text { AI-2 independently calculates sample characteristics and } \\
\text { statistical estimates for solving standard problems in agronomy } \\
\text { AI-3 independently applies information and communication } \\
\text { technologies when searching for missing information and } \\
\text { calculating sample characteristics and statistical estimates }\end{array}$ & $\begin{array}{c}9-10 \text { (more than } \\
90 \%)\end{array}$ \\
\hline
\end{tabular}

Reference to problems of this nature is due to the lack of such in the educational literature. Considering the textbooks and manuals recommended for the discipline B1.O.09 Mathematics and Mathematical Statistics for major 35.03.04 Agronomy, we noticed that in textbooks either missing the "Mathematical Statistics", or there are insufficient number of problems to solve, and relevant content problems and case tasks are missing completely, which does not allow enough time to work on formation of professional competences. Let's analyze the module "Statistical evaluation of distribution parameters".

The first edition of "Mathematics and Mathematical Statistics" by V.F. Komogortsev [3] contains chapter 6. Fundamentals of Mathematical Statistics §2. Point and interval evaluations of numerical characteristics of the general population [3, p. 151]. For an independent solution, students are offered 3 problems of mathematical content, there are no problems of profile content and case tasks.

Exercises 
1. In order to study the size $X$ of some similar products produced by the plant, 50 products were randomly selected. Their size distribution (statistical distribution of the sample) is as follows (Table 2.):

Table 2. Statistical distribution of products.

\begin{tabular}{|c|c|c|c|c|c|c|}
\hline$x_{i}$ & $107.8-$ & $108.0-$ & $108.2-$ & $108.4-$ & $108.6-$ & $108.8-$ \\
$(\mathrm{sm})$ & -108.0 & -108.2 & -108.4 & -108.6 & -108.8 & -109.0 \\
\hline$n_{i}$ & 1 & 4 & 16 & 18 & 8 & 3 \\
\hline
\end{tabular}

To find a confidence interval that estimates with reliability $\gamma=0.95$ the average size of products produced by the plant.

Answer: (108.39; 108.51).

2. When determining a certain value a experimentally, 5 repeated experiments were carried out, which gave the following results:

$$
0.640 ; \quad 0.652 ; 0.656 ; 0.664 ; 0.670
$$

a) What is the probability that the true value a of the measured value differs from the average result of the measurements by no more than 0.01 ?

b) In what confidence interval $\left(x_{6}-\delta ; x_{6}+\delta\right)$ with reliability $\gamma=0.99$ is the desired value a?

Answer: a) $\gamma \approx 0.87$; b) $(0.633 ; 0.680)$.

Quality control of a large batch of products is carried out selectively. What should be the minimum sample size so that with the reliability of $\gamma=0.99$ it can be stated that the deviation of the average service life of the product in the sample differs from the average service life in the entire test batch by no more than 3 hours (in one direction or the other)? According to the results of the preliminary (trial) sample, $s_{\vec{B}}=10$ hour was obtained.

Answer: 74. [3, pp. 159-160].

The second edition of the author Berezina, N.A. Mathematics [4] does not contain a section devoted to mathematical statistics.

The third edition of the author Nazarov A.I. The course of mathematics for nonmathematical specialties and bachelor's degrees [5, p. 533] contains section 3 Estimation of distribution parameters. The section is illustrated with examples, but the problems offered to students for solving are not included in the publication.

The fourth edition of the author Shipachev V.S. Higher Mathematics [6] as well as the edition of Berezina N.A. Mathematics does not contain the module "Statistical estimates of distribution parameters".

In such a way, we were convinced of the insufficient number of problems that contribute to the formation of general professional competencies through mathematical disciplines, which is the object of this study.

\section{Conclusions}

In this article, we have considered the possibility of applying profile content problems and case tasks in the study of the discipline B1.O.09 Mathematics and Mathematical Statistics by future farmers. It should be noted that in the educational publications available today, tasks of this nature are not reflected or contained in insufficient quantity. For the formation of GPC-1, it is not enough to learn only to determine the necessary formula, perform calculations, it is important to be able to formulate the problem, choose research methods, analyze the result, be able to interpret the data, justify the conclusions obtained, and make predictions. In our opinion, this approach will not only form the necessary mathematical apparatus for students but will also increase the strength and awareness of knowledge, which will contribute to the meaningful use of mathematical apparatus in professional activities. 


\section{References}

1. FSES for Bachelor's Degree Programs: 35.03.04 Agronomy, http://fgosvo.ru/

2. O.B. Smirnova, N.V. Shchukina, Collection of tasks on probability theory and mathematical statistics (Omsk: Publishing house of FSEI HPE OmSAU) 64 (2006).

3. V.F. Komogortsev, Mathematics and mathematical statistics: textbook for bachelors in major 35.03.03, 35.03.04, 35.03.07 (Bryansk: Publishing House of the Bryansk SAU) 164 (2019)

4. N.A. Berezina, E.L. Maxina, Mathematics (Moscow: INFRA-M) 175 (2013)

5. A.I. Nazarov, I.A. Nazarov, Mathematics course for non-mathematical specialties and bachelor's degree courses (SPb.; Moscow; Krasnodar: Lan) 576 (2013)

6. V.S. Shipachev, Higher Mathematics (Moscow: SC INFRA-M) 479 (2021)

7. P.V. Kiyko, Economic and mathematical methods and models (Berlin: Direct-Media) 122 (2016)

8. P.V. Kiyko, N.V. Shchukina, Electronic scientific and methodological journal of Omsk SAU, 4(7), 22 (2016)

9. P.V. Kiyko, N.V. Shchukina, International Journal of Economic Research, 14(7), 59-75 (2017)

10. M. I. Grabar, K. A. Krasnyanskaya, Application of mathematical statistics in pedagogical research. Nonparametric methods (M.: Pedagogy) 71 (1977)

11. O.B. Smirnova, N.V. Shchukina, Tasks for typical calculations in mathematical disciplines (Berlin: Direct-Media) 146 (2016)

12. O. Korchinskaya, I. Ivanova, N. Shchukina, M. Mendziv, Proceedings of the International Scientific Conference The Fifth Technological Order: Prospects for the Development and Modernization of the Russian Agro-Industrial Sector (2019)

13. G.V. Redreev, P.V. Kiyko, N.V. Shchukina, 2019 International Multi-Conference on Industrial Engineering and Modern Technologies (FarEastCon) (Vladivostok, Russia) 01-04 (2019) 